\title{
Effects of endocrine modulating substances on reproduction in the hermaphroditic snail Lymnaea stagnalis $\mathrm{L}$
}

\author{
P. Czech ${ }^{\mathrm{a}}, \mathrm{K}$. Weber ${ }^{\mathrm{b}}$, D.R. Dietrich ${ }^{\mathrm{c}, *}$ \\ ${ }^{a}$ RCC Ltd., Environmental Chemistry and Pharmanalytics Division, Zelgliweg 1, CH-4452 Itingen, Switzerland \\ ${ }^{\mathrm{b}}$ RCC Ltd. Toxicology Division, Zelgliweg 1, CH-4452 Itingen, Switzerland \\ ${ }^{\mathrm{c}}$ Environmental Toxicology, University of Konstanz Jacob-Burckhardtstr. 25, D-78434 Konstanz, Germany
}

\begin{abstract}
Various man-made agents like pesticides, industrial chemicals and some natural substances have the potential to alter hormonal pathways that regulate reproductive processes in certain species of wildlife. Until now, only a few investigations have been undertaken to determine the effects of these substances on reproductive capacities (fecundity and fertility) in exposed invertebrate aquatic species. In this study one of the most abundant mollusc of European limnic systems, the hermaphroditic gastropod Lymnaea stagnalis was investigated to determine the effects of endocrine modulating substances on reproductive parameters. Known endocrine modulating substances were tested using the following nominal concentrations; Tributyltin (TBT in $\mathrm{ng} \mathrm{Sn} / \mathrm{l}$ ) and $\beta$-sitosterol at 1,10 and $100 \mathrm{ng} / \mathrm{l}$, respectively, and 4-nonylphenol (4-NP) at 1, 10 and $100 \mu \mathrm{g} / \mathrm{l}$. In addition, experiments were carried out with 1, 10 and $100 \mathrm{ng} / \mathrm{l}$ of $t$-methyltestosterone. All the testing was carried out on recently matured adults of Lymnaea. Fifteen to twenty snails per treatment were exposed for between 7 and 12 weeks in a semi-static test with a weekly exchange of testwater. Shell height and weight and mortality of the adults, egg production, hatching rate of the eggs, and histopathology of the adult snails were analysed. The same parameters were investigated on $F_{1}$ generation snails from exposed parents at two dates (1 week after exposure and at the end of the exposure duration). Treatments with TBT and 4-NP had only slight effects on the egg production of the adults and hatching rate of the eggs. However, increased histopathological changes were observed in epithelial tissues of the adult snails, e.g. lung and foot also characterised by extreme inflammatory processes. While $\beta$-sitosterol and $t$-methyltestosterone had no effect on the shell height and weight or the mortality of adult snails nor on the egg production or ensuing egg hatching rate, $\beta$-sitosterol treated snails presented a distinct atrophy of the albumen gland and so did $t$-methyltestosterone, albeit with a lower degree of atrophy. The observed histopathological effects due to exposure to tributyltin or 4-NP are suggested to lead to long-term adverse reproductive effects mediated by an impairment of the fitness of the snails. In the experiments the steroid-dependant ( $\beta$-sitosterol and $t$-methyltestosterone) degeneration of the albumen gland caused no obvious adverse effects on the fecundity nor fertility of the adults or on $\mathrm{F}_{1}$-generation. However, the impact on fertility following a prolonged exposure to high concentrations of the phytoestrogen cannot be predicted.
\end{abstract}

* Corresponding author. Tel.: + 49-7531-883518; fax: + 49-7531-883170.

E-mail address: daniel.dietrich@uni-konstanz.de (D.R. Dietrich). 
Keywords: Endocrine modulators; Lymnaea stagnalis; Reproductive parameters; Histopathology; TBT; Nonylphenol; $\beta$-sitosterol; $t$-methyltestosterone

\section{Introduction}

Various man-made agents like pesticides, industrial chemicals and some natural substances present in the environment, found in waste-, ground- and river water have been shown to affect the endocrine regulatory system in certain species of wildlife, e.g. birds, reptiles, fish, and amphibians (Colborn et al., 1993; Jobling et al., 1998). Such endocrine modulating compounds have the potential to perturb sensitive hormonal pathways that regulate reproductive functions. However, until today only a few investigations have been undertaken to determine the effects of these substances on reproductive capacities (fecundity and fertility) in the exposed invertebrate aquatic species (Schulte-Oehlmann et al., 1995; Oehlmann et al., 1996; Schulte-Oehlmann et al., 1997) and therefore, to evaluate the ecological implications of exposure to such endocrine modulating compounds. Most attention, with regard to potential detrimental effects on reproductive capacities has been given to fish (Arcand-Hoy and Benson, 1997). Invertebrates, which are important representatives of the primary consumers in limnic systems and therefore an important link in the aquatic food chain, have so far been virtually ignored.

As the very existence of mollusc populations depends on the capacity of adult molluscs to produce high numbers of offspring, any change in either fecundity (number of eggs per sperm) or fertility (number of fertile eggs or sperm) of the adults could severely endanger the individual populations. Developmental and reproductive toxicity may occur during larval development or at the juvenile or adult stage. Exposure to endocrine modulating compounds at maturity, may affect the normal cascade of events leading to the production of eggs and sperm or affect the normal activity of sexual organs at the reproductive stage. The xenobiotic derived hormonal imbalance or biochemical interaction can also lead to reproductive impairment in the ensuing generations (Tate et al., 1997). Consequently, any investigation looking at the effects of xenobiotics on the reproductive capacities (fecundity and fertility) of a given species should, wherever possible, include mortality, weight and size, as well as histopathological data of the adults, fecundity of the adults and the ensuing $F_{1}$ generation, as well as the fertility/hatchability of the eggs. The aim of this study was to investigate the potential adverse effects of three known endocrine modulating compounds ( $\beta$-sitosterol, 4-nonylphenol, Tributyltin) (Mac Latchy and Van der Kraak, 1995; Lech et al., 1996; Bettin et al., 1996) and one unknown endocrine modulator ( $t$ - methyltestosterone) on the reproductive capacities in the hermaphroditic gastropod Lymnaea stagnalis, one of the most abundant mollusc of European limnic systems. In order to ensure transferability of the laboratory data to an environmental setting, the testing concentrations of xeniobiotics chosen included those levels reportedly found in the environment (Mac Latchy and Van der Kraak, 1995; Blackburn and Waldock, 1995; Fent, 1996).

\section{Materials and methods}

\subsection{Test organisms}

Sexually mature L. stagnalis $\mathrm{L}$. (shell length $25-35 \mathrm{~mm}$ ) were obtained from our laboratory culture of egg masses that were laid on the same day. Until maturity (about 3 months) snails were kept in 20-100 1 glass aquaria filled with at least 1-day-old dechlorinated tap water. The water temperature was approximately $22^{\circ} \mathrm{C}$ and the 16:00-h light:08:00-h dark rhythm. Snails were fed twice a week, alternately, with Tetraphyll and fresh lettuce. 


\subsection{Test substances and nominal concentrations}

$\beta$-sitosterol (Fluka Chemie AG, Kat. Nr. 85451): 1, 10 and $100 \mathrm{ng} / \mathrm{l}$; 4-nonylphenol (4-NP) (Fluka Chemie AG, Kat. Nr. 74430): 1, 10 and $100 \mu \mathrm{g} / \mathrm{l}$; Tributyltin (TBT) (Fluka Chemie AG, Kat. Nr. 90892): 1,10 and $100 \mathrm{ng} \mathrm{Sn/1;} t$ methyltestosterone (Fluka Chemie AG, Kat. Nr. 69240): 1, 10 and $100 \mathrm{ng} / \mathrm{l}$.

Stock solutions were prepared in Ethanol and after application solvent concentration resulted in $0.01 \%$ Ethanol. The animals of the solvent group received only ethanol.

\subsection{Test conditions}

\subsubsection{Effects in the $F_{0}$}

For each treatment, 15-20 sexually mature Lymnaea were kept in 201 all-glass aquaria, in artificial dechlorinated freshwater and exposed under semi-static test conditions (weekly exchanges of water), up to a maximum exposure duration of 12 weeks (see Fig. 1). The water temperature was approximately $22^{\circ} \mathrm{C}$ and the light:dark rhythm was 16:00 h:08:00 h. Snails were fed daily with $30 \mathrm{mg}$ per individual alternately with tetraphyll and tetramin. With each testwater change the egg clutches were counted and transferred into new glass aquaria and kept under normal culturing conditions until hatching.

\subsubsection{Effects in the $F_{1}$}

Effects on the reproductive capacities of the $F_{1}$ generation were determined out on two dates. From each concentration tested, samples of 1520 hatchlings were taken from clutches that were laid in the first week of exposure and at the end of the experiment, i.e. after 7 or 8 weeks of exposure. The young snails were maintained under normal culture conditions until they became sexually mature (after approximately 3 months). Then five mature specimens of each treatment were randomly picked and over a period of 7 weeks their reproductive parameters (fertility/fecundity) recorded, as explained under Section 2.4.

\subsection{Endpoints}

At weekly intervals, adult mortality and reproductive data were recorded. Reproductive parameters were analysed as follows. Fecundity, mean number of egg clutches per animal per week fertility/hatchability, clutches were visually appraised, the number of successful and unsuccessful clutches with $>50$ and $<50 \%$ hatched eggs, respectively, was recorded. Under control condi-

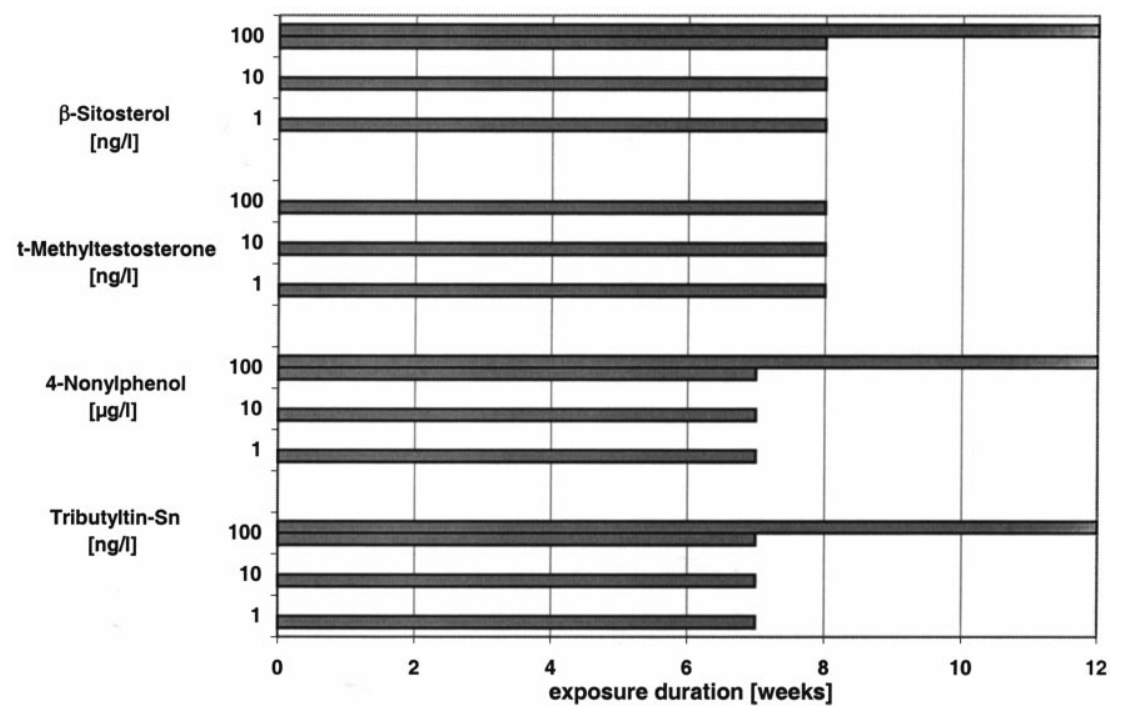

Fig. 1. Exposure duration of the experiments with the 4 different compounds at the respective concentrations. 
Table 1

Histopathology after 7 weeks of treatment ${ }^{\mathrm{a}}$

\begin{tabular}{|c|c|c|c|c|}
\hline Treatment & Concentration & Organ $(n)$ & Symptom & Gravity \\
\hline Control & - & - & - & - \\
\hline Solvent & $100 \mu \mathrm{g} / 1$ Eth.abs. & - & - & - \\
\hline 4-Nonylphenol & $1,10,100 \mu \mathrm{g} / 1$ & - & - & - \\
\hline \multirow[t]{2}{*}{ Tributyltin } & $1 \mathrm{ng} \mathrm{Sn} / 1$ & - & - & - \\
\hline & $10 \mathrm{ng} \mathrm{Sn} / 1$ & - & - & - \\
\hline
\end{tabular}

${ }^{a}$ For each treatment five surviving specimens were killed at the end of the experiment, fixed and stained with hematoxylin-eosin and 3-4 $\mu \mathrm{m}$ thick tissue sections microscopically examined. $(n)=$ number of animals with findings related to preceding organ; AG, albumen gland; DE, dermis; F, foot; LU, lung; MA, mantle; PR, prostate gland; d, degenerative; i, inflammatory; gravity: 1 (minimal), 2 (weak), 3 (medium), 4 (strong), 5 (extreme).

tions the eggs developed and the young snails hatched within approximately 2 weeks. If no disturbance of the egg development occurred, only a few eggs (normally less then 20\%) were left unhatched in the clutch membrane 3 weeks after the clutch was laid. Disturbance of the egg development was, therefore, judged by the percentage of undeveloped sterile eggs or eggs in different developmental stages found in the clutch at three weeks post clutch laying. The fertility/hatchability was expressed as mean percentage of successful clutches per total clutches, recorded weekly.

At the end of the exposure time $(7,8$ or 12 weeks) the surviving animals were anaesthetised in $7 \% \mathrm{MgCl}_{2}$. Before cracking the shell, the weight of the adults and shell height were measured. For the histopathological examination, animals were fixed in Bouin's solution. Thick paraffin 3-4 $\mu \mathrm{m}$ embedded tissue sections were deparaffinised, stained with Hematoxylin-Eosin and all organs examined microscopically.

\subsection{Statistical analysis}

Significant differences in weight and fecundity (egg production) in between treatments, compared to that of the respective controls, were determined using an analysis of variance (ANOVA) analysis of the standardised means of each group, followed by a Dunnett's multiple comparison test. A Kol-
mogorrof-Smirnov and Bartlett's test were employed to test the normality of the data distribution and the homogeneity of the variances, respectively. If data were not normally distributed, a Kruskal-Wallis test with multiple comparison according to Tukey was applied.

\section{Results}

\subsection{Mortality}

No significant increase in mortality was observed in either the control or treatment groups throughout the whole duration of all experiments in the exposed $\mathrm{F}_{0}$-generation nor in the immediate succeeding $F_{1}$-generation (data not shown).

\subsection{Shell height and weight}

None of the four compounds tested had any significant effect on shell height and weight, when determined at 8 and 12 weeks of the respective treatments. However, a significantly $(P<0.05$, Dunett's test) lower weight, compared to the respective average weight of the control group, was recorded at the lowest concentration ( $1 \mathrm{ng} \mathrm{Sn} / \mathrm{l})$ of Tributyltin at 7 weeks (data not shown). No effects were detectable in the immediate $\mathrm{F}_{1^{-}}$generation. 


\section{Histopathology}

\subsection{Seven to eight weeks of exposure}

Seven weeks of exposure to 4-NP resulted in no observable histopathological changes at any concentration level $(1,10$ or $100 \mu \mathrm{g} \mathrm{NP} / 1)($ Table 1$)$.

For snails treated with Tributyltin, the animals of the highest test concentration (100 ng Sn/l) showed marked degenerative effects (tissue necrosis) in the epithelial tissue of the lung and foot, also characterised by a severe inflammatory response (macrophage and amoebocyte infiltration) (Fig. 2A-D and Table 1).

No such changes were observed at the two lower concentrations of Tributyltin (1 and $10 \mathrm{ng}$ $\mathrm{Sn} / \mathrm{l})$ (Table 1).

Eight weeks of exposure to the highest concentration of the phyto-estrogen $\beta$-sitosterol (100 $\mathrm{ng} / \mathrm{l})$ resulted in marked atrophy of the albumen gland (accessory sexual organ) (Fig. 2E and F and Table 2). The beginning of degenerative processes of the albumen gland was also observed at the highest concentration of $t$-methyltestosterone (100 $\mathrm{ng} / \mathrm{l}$ ), while histopathological changes in the epithelia of the lung and foot were absent.

\subsection{Twelve weeks of exposure}

Twelve weeks of exposure to the highest concentrations of 4-NP $(100 \mu \mathrm{g} / \mathrm{l})$ and Tributyltin (100 ng Sn/l) both resulted in marked degenerative effects on epithelial tissues of lung and foot and inflammatory response similar to that found with $100 \mathrm{ng} \mathrm{Sn} / 1$ Tributyltin after 7 weeks of exposure (Fig. 2A-D and Table 3).

Twelve weeks in Lymnaea exposed to $\beta$-sitosterol $(100 \mathrm{ng} / 1)$, resulted in no histopathological changes of the epithelia of the lung and foot. However, the atrophy of the albumen gland, as already observed after 8 weeks of exposure, was more profound (Fig. 2E and F and Table 3).

The histopathological examination of the snails' ovotestis (hermaphroditic gonad) did not reveal any treatment related effects for any of the compounds tested at any exposure duration.

The $\mathrm{F}_{1}$-generation did not present with any histopathological changes (data not shown).

\subsection{Fecundity}

\subsubsection{Seven to eight weeks of exposure}

No effects on fecundity of Lymnaea were observed following 7-8 weeks of exposure to $\beta$ sitosterol and $t$-methyltestosterone (Fig. 3B). No effect on fecundity was suggested at the highest concentration of 4-NP $(100 \mu \mathrm{g} / \mathrm{l})$ (Fig. 3A). The exposure to the highest concentration of tributyltin $(100 \mathrm{ng} \mathrm{Sn} / \mathrm{l})$ induced a significantly $(P<$ 0.05 , Dunnett's test) reduced egg laying rate when compared with controls (Fig. 3A).

\subsubsection{Twelve weeks of exposure}

Twelve weeks exposure to $\beta$-sitosterol (100 ng/l) appeared to result in a higher egg laying rate (Fig. 3C), although this effect was not statistically proven. The treatment with the highest concentration of 4-NP $(100 \mu \mathrm{g} / \mathrm{l})$ induced a significantly lower fecundity than in control snails $(P \leq 0.05$, Student's $t$-test) (Fig. 3C). An even lower egg laying rate was observed in the treatment with tributyltin (100 ng Sn/l), although statistical significance was not achieved due to the high variance (Fig. 3C).

\subsection{Fertility/hatchability}

Of the control egg clutches, 89.2 and $81.0 \%$ hatched successfully ( $>50 \%$ hatching) at 7 and 12 weeks, respectively (Fig. 4A, B.). Twelve weeks exposure to $100 \mathrm{ng} / 1 \beta$-sitosterol resulted in $73.2 \%$ successfully hatched clutches (Fig. 4B.).

No significant differences in hatching rates were observed following treatment with the highest concentrations of $4 \mathrm{NP}(100 \mu \mathrm{g} / \mathrm{l})$ and tributyltin (100 ng Sn/l), respectively. However, the percentage of successfully hatched egg clutches was lower than in the respective solvent control in both cases and at 7 and 12 weeks (Fig. 4A and B), respectively.

\subsection{Reproduction of $F_{1}$ generation}

No statistical differences or trends were detected between egg laying rates and hatching rates of $\mathrm{F}_{1}$-generation of endocrine xenobiotica -exposed Lymnaea and the respective controls (data not shown). 


\section{Discussion}

No discernible effects on fecundity or fertility/ hatchability of Lymnaea were recorded at the lowest and intermediate concentrations of the four compounds tested. This observation is supported by the fact that no gonadal pathology changes were observed for any of the compounds

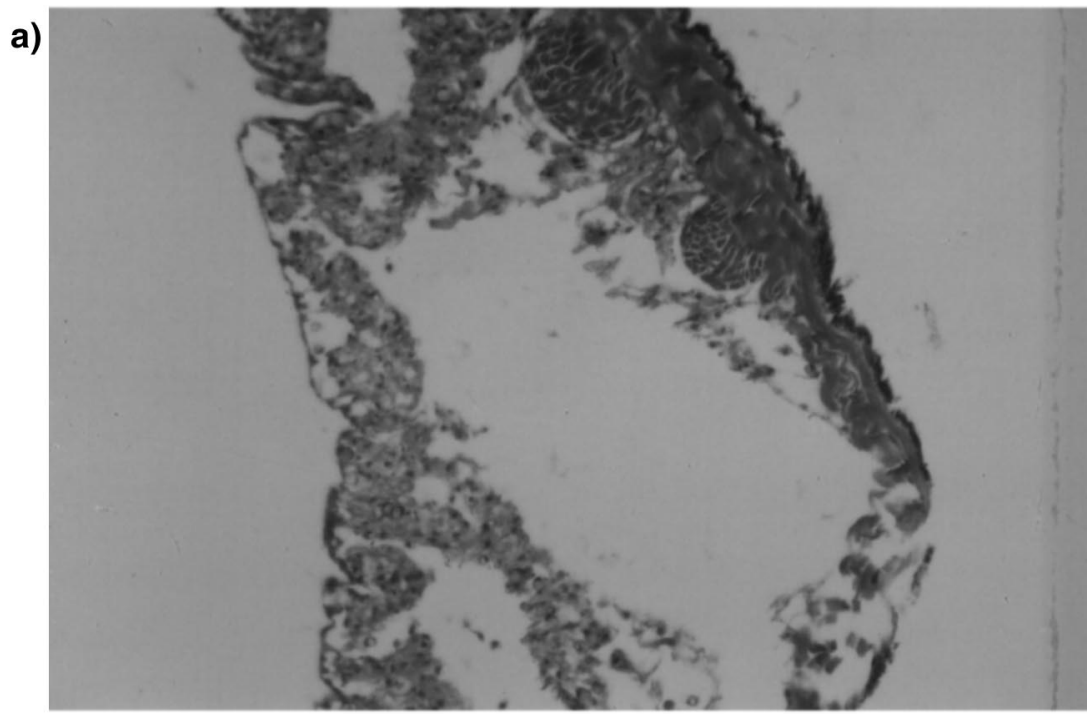

b)

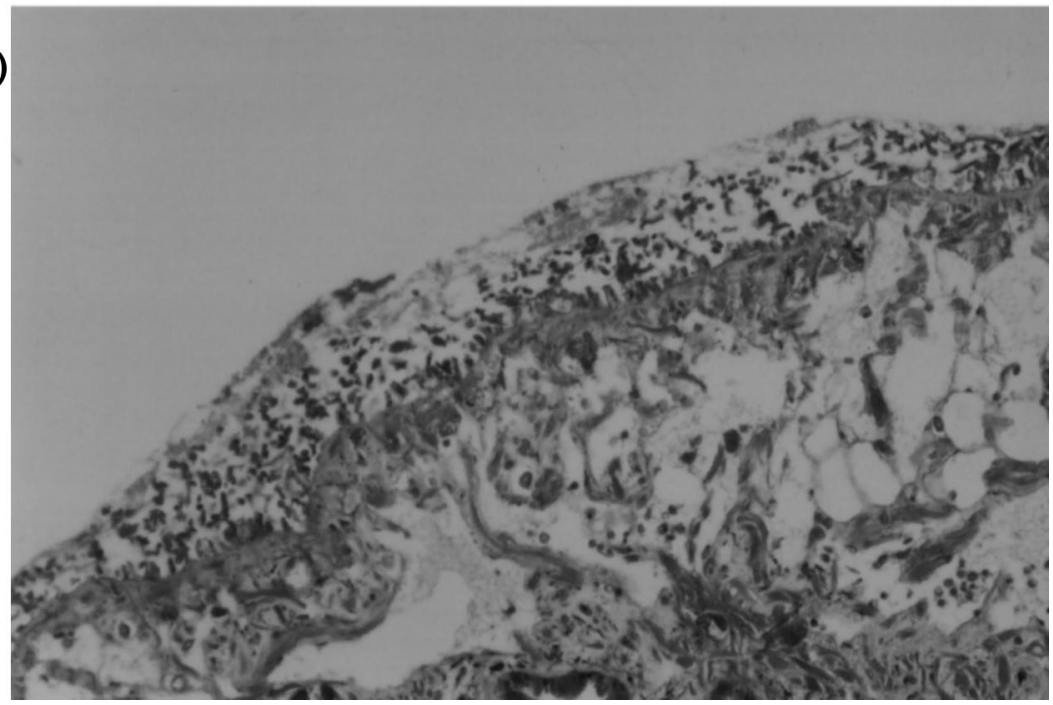

Fig. 2. (A-F) Photographs. (A) Lung of control Lymnaea. Without pathological findings. (B) Lung of Lymnaea following exposure to $100 \mathrm{ng} / \mathrm{I} \mathrm{TBT}$ or $100 \mu \mathrm{g} / 14-\mathrm{NP}$. The epithelium is disconnected and infiltrated by amoebocytes (macrophages). There are various foci of necrotic cells. (C) Foot of control Lymnaea. With normal ciliated epithelium. (D) Foot of Lymnaea following exposure to $100 \mathrm{ng} / \mathrm{I}$ TBT or $100 \mu \mathrm{g} / 1$ 4-NP. Most of the cilia of the epithelium are disappeared. There is a high amount of infiltrating amoebocytes present. The epithelium layers are disorganised compared to the normal stratification. (E) Albumen gland of control Lymnaea. Cells are rich of cytoplasma and large globuli. (F) Albumen gland of Lymnaea following exposure to $100 \mathrm{ng} / 1 \beta$-sitosterol. Cells show marked atrophy consisting of loss of globuli, shrunken cells and moderate tubular dilation. Nuclei which are considered to be pycnotic, are not indicative for degeneration, alone. 
c)

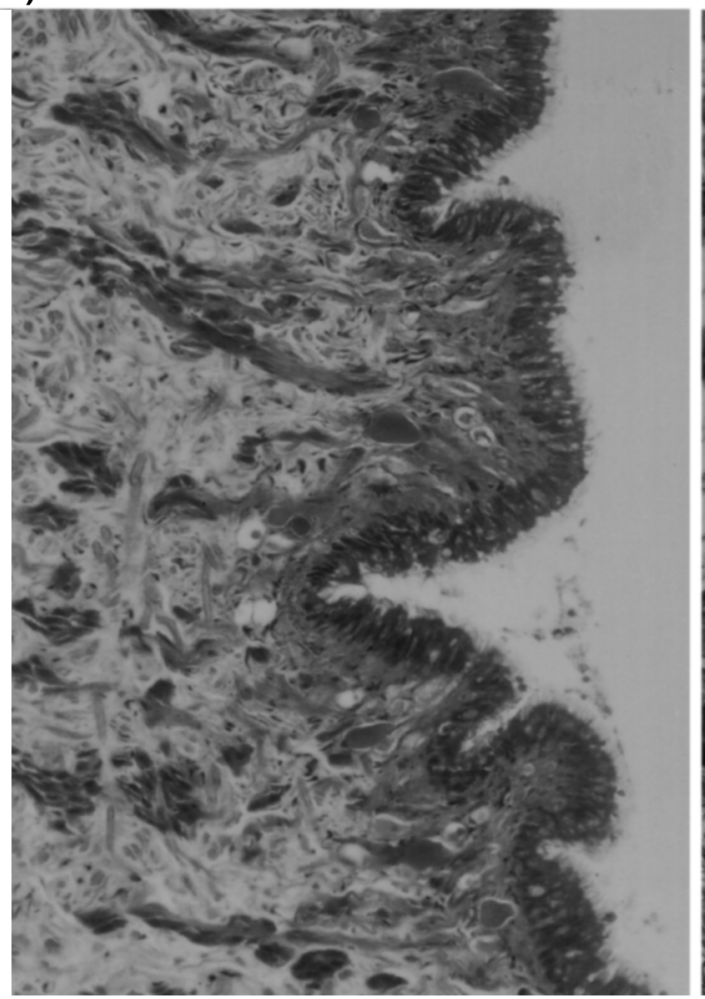

d)

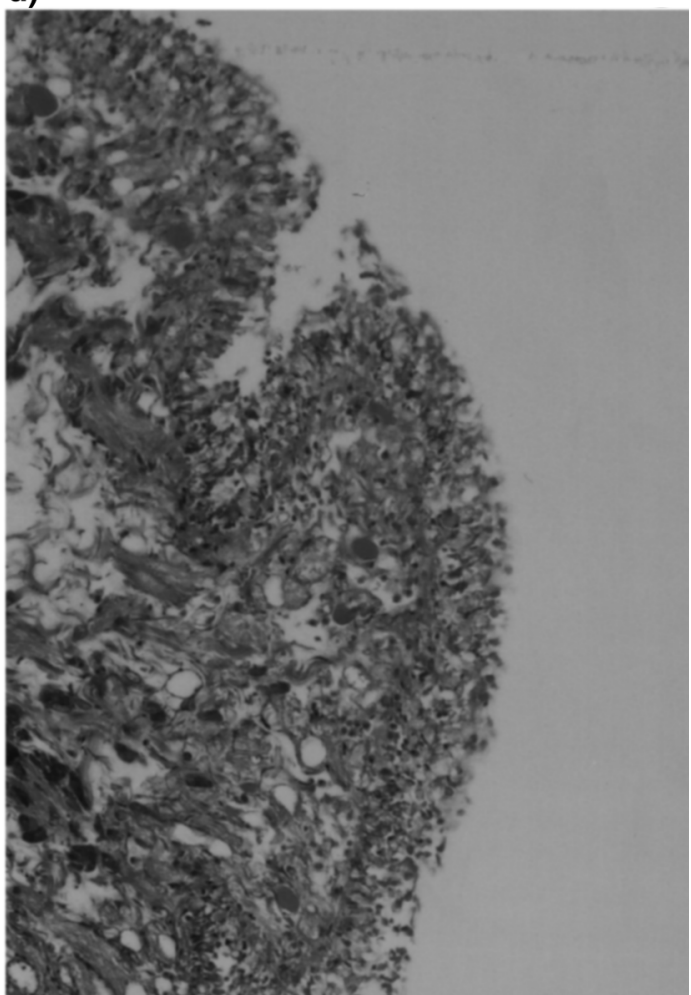

Fig. 2. (Continued)

tested. Furthermore, neither $\beta$-sitosterol nor $t$ methyltestosterone, whose androgenic activities have been demonstrated in female mosquitofish (Denton and Howell, 1989; Ellis et al. 1999), had any demonstrable effect on Lymnaea, with the exception of the fact that the highest concentrations of the two steroids used induced atrophy of the albumen gland. The latter effect may also be seen in context with the observed lower hatchability of clutches from adults exposed to the highest concentrations of $\beta$-sitosterol. However, this lowered hatchability was not statistically significant. Furthermore, the results indicated that chronic exposure to the phytoestrogen $\beta$-sitosterol seemed to stimulate egg production in Lymnaea but at the cost of egg quality.

In contrast, high concentrations of the two non-steroidal industrial compounds 4-NP and tributyltin significantly lowered fecundity, and in the case of tributyltin, also fertility/hatchability. The effects of the latter, do not however, appear to be related to the putative endocrine modulating capacity of these two compounds, especially as lowered fecundity and hatchability occurred simultaneously with severely increased histopathological changes in the lung and foot of the adult Lymnaea. A generally lowered health status could arguably result in a lowered reproductive activity.

The investigation of the impact on the $F_{1}$ generation of exposed Lymnaea did not demonstrate any discernible effects of the compounds tested on the reproductive capacity of the mature Lymnaea $\mathrm{F}_{1}$-generation. Although these $\mathrm{F}_{1}$ experiments 
suggested that none of the four compounds tested had any endocrine modulating activity in Lymnaea, caution with the interpretation of these results is advised. Especially since a recent study by Tate et al. (1997) reported effects on reproduction of Pseudosuccinea columnella following exposure to Glyphosate in the $F_{3}$, but not in the $F_{1}$ and $\mathrm{F}_{2}$-generations.
In summary, the adverse effects of 4-NP and tributyltin observed in Lymnaea were clearly associated with high concentrations only. These nominal concentrations are about one order of magnitude higher than those analytical concentrations generally observed in the environment. In addition, the effects observed in Lymnaea did not appear to be associated with endocrine modulat-
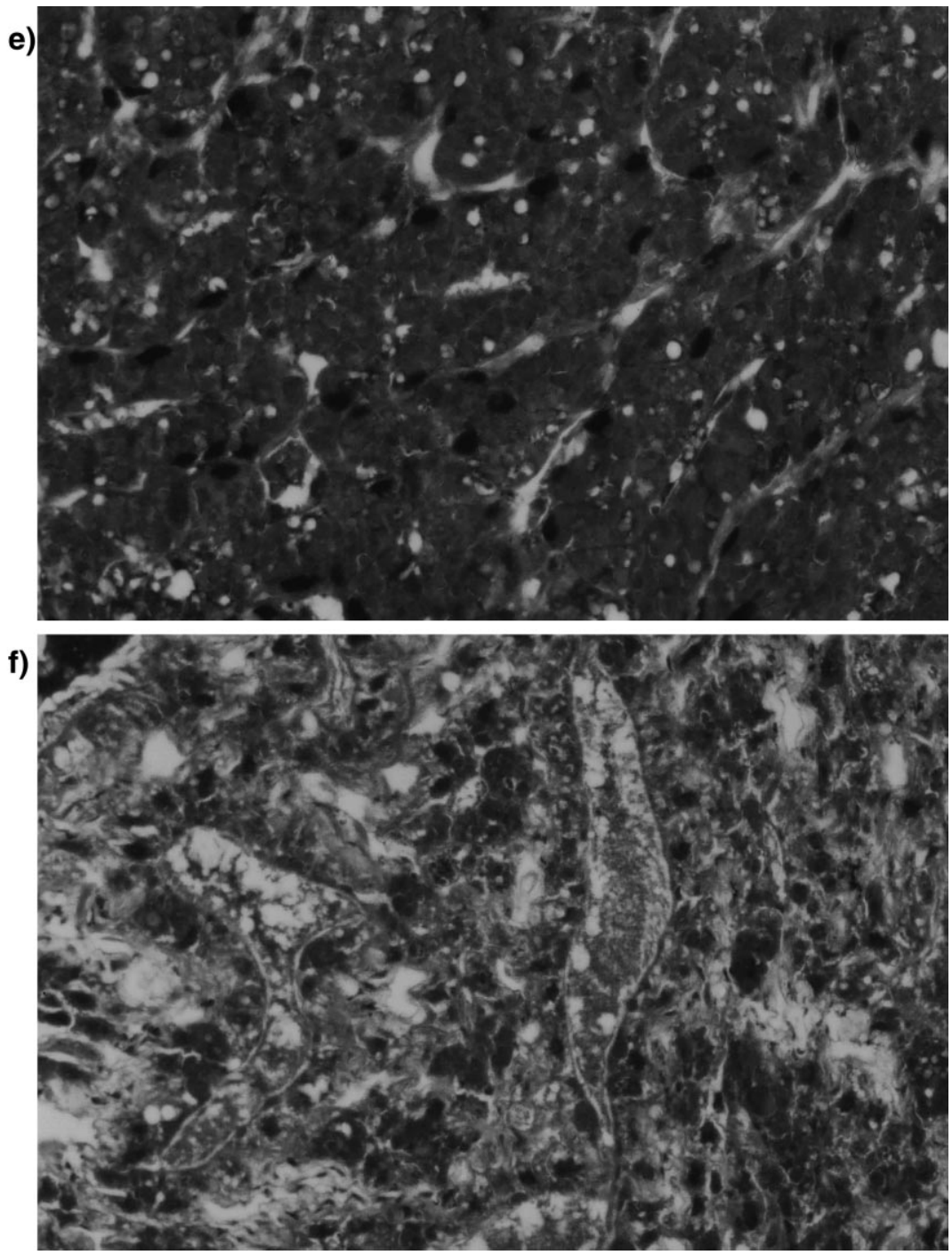

Fig. 2. (Continued) 
Table 2

Histopathology after 8 weeks of treatment ${ }^{\mathrm{a}}$

\begin{tabular}{|c|c|c|c|c|}
\hline Treatment & Concentration & Organ $(n)$ & Symptom & Gravity \\
\hline Control & - & - & - & - \\
\hline Solvent & $100 \mu \mathrm{g} / 1$ Eth.abs. & - & - & - \\
\hline \multirow[t]{3}{*}{$\beta$-Sitosterol } & $1 \mathrm{ng} / \mathrm{l}$ & - & - & - \\
\hline & $10 \mathrm{ng} / 1$ & - & - & - \\
\hline & $100 \mathrm{ng} / 1$ & AG (4), PR (1) & $\mathrm{d}, \mathrm{d}$ & 1.8 \\
\hline$t$-Methyl-testosterone & $100 \mathrm{ng} / 1$ & AG (1), PR (1) & $\mathrm{d}, \mathrm{d}$ & 2 \\
\hline
\end{tabular}

\footnotetext{
${ }^{a}$ For each treatment five surviving specimens were killed at the end of the experiment, fixed and stained with hematoxylin-eosin and 3-4 $\mu \mathrm{m}$ thick tissue sections microscopically examined. $(n)$, number of animals with findings related to preceding organ; AG, albumen gland; DE, dermis; F, foot; LU, lung; MA, mantle; PR, prostate gland; d, degenerative; i, inflammatory; gravity: 1 (minimal), 2 (weak), 3 (medium), 4 (strong), 5 (extreme).
}

Table 3

Histopathology after 12 weeks of treatment ${ }^{\mathrm{a}}$

\begin{tabular}{|c|c|c|c|c|}
\hline Treatment & Concentration & Organ $(n)$ & Symptom & Gravity \\
\hline Control & - & - & - & - \\
\hline Solvent & $100 \mu \mathrm{g} / 1$ Eth.abs. & - & - & - \\
\hline 4-Nonylphenol & $100 \mu \mathrm{g} / 1$ & LU (2), MA (2), F (3), DE (5) & $\mathrm{i}, \mathrm{d}, \mathrm{d}, \mathrm{d}+\mathrm{i}$ & $2.0-4.2$ \\
\hline Tributyltin & $100 \mathrm{ng} \mathrm{Sn} / 1$ & MA (1), DE (4) & $\mathrm{i}+\mathrm{d}, \mathrm{d}$ & $2.0-3.0$ \\
\hline$\beta$-Sitosterol & $100 \mathrm{ng} / 1$ & $\mathrm{AG}(3)$ & $\mathrm{d}$ & 3.7 \\
\hline
\end{tabular}

${ }^{\text {a }}$ For each treatment three surviving specimens were killed at the end of the experiment, fixed and stained with hematoxylin-eosin and 3-4 $\mu \mathrm{m}$ thick tissue sections microscopically examined. $(n)$, number of animals with findings related to preceding organ; AG, albumen gland; DE, dermis; F, foot; LU, lung; MA, mantle; PR, prostate gland; d, degenerative; i, inflammatory; gravity: 1 (minimal), 2 (weak), 3 (medium), 4 (strong), 5 (extreme).

ing activity but rather appeared to have resulted from the cytotoxic or inflammatory activity of the respective compounds.

A varying appearance in structure of the albumen gland in conjunction with different physiological states due to metabolic processes and sexual activity has been known for decades (Holm, 1945). Indeed, the albumen glands of control snails, that were killed immediately after oviposition, fixed, embedded and stained showed dilation of the tubuli. However, no cell degradation or lysis was observed. Thus the degenerative effect of the phytoestrogen $\beta$-sitosterol on the albumen gland cells appears to be a compound specific yet reversible exposure duration-depen- dant process without any bearing on the fertility or egg quality.

However, whether or not endocrine disruption occurred cannot be answered by the experimental design as no endogenous hormone titres or changes at hormone receptor levels were investigated. In contrast, recent studies with nonhermaphroditic prosobranch snails demonstrated that exposure to very low ambient concentrations of organotin compounds resulted in a masculinisation and sterilisation and therefore in reproductive failure in the female snails (Oehlmann et al., 1998; Schulte-Oehlmann et al., 1997). The phenomenon of intersex and imposex (pseudohermaphrodism) presented by these highly 
sensitive species (Bauer et al., 1997; Minchin et al., 1997; Oehlmann et al., 1997), may be a species or even sub-class specific effect. Although the results of our study not support the conclusion that snails in general are sensitive for known endocrine disrupters, the data emphasise that the selection of the test species is most crucial, i.e. that specific species or even sub-classes of the class Gastropoda may be at a higher risk than others of the same class.
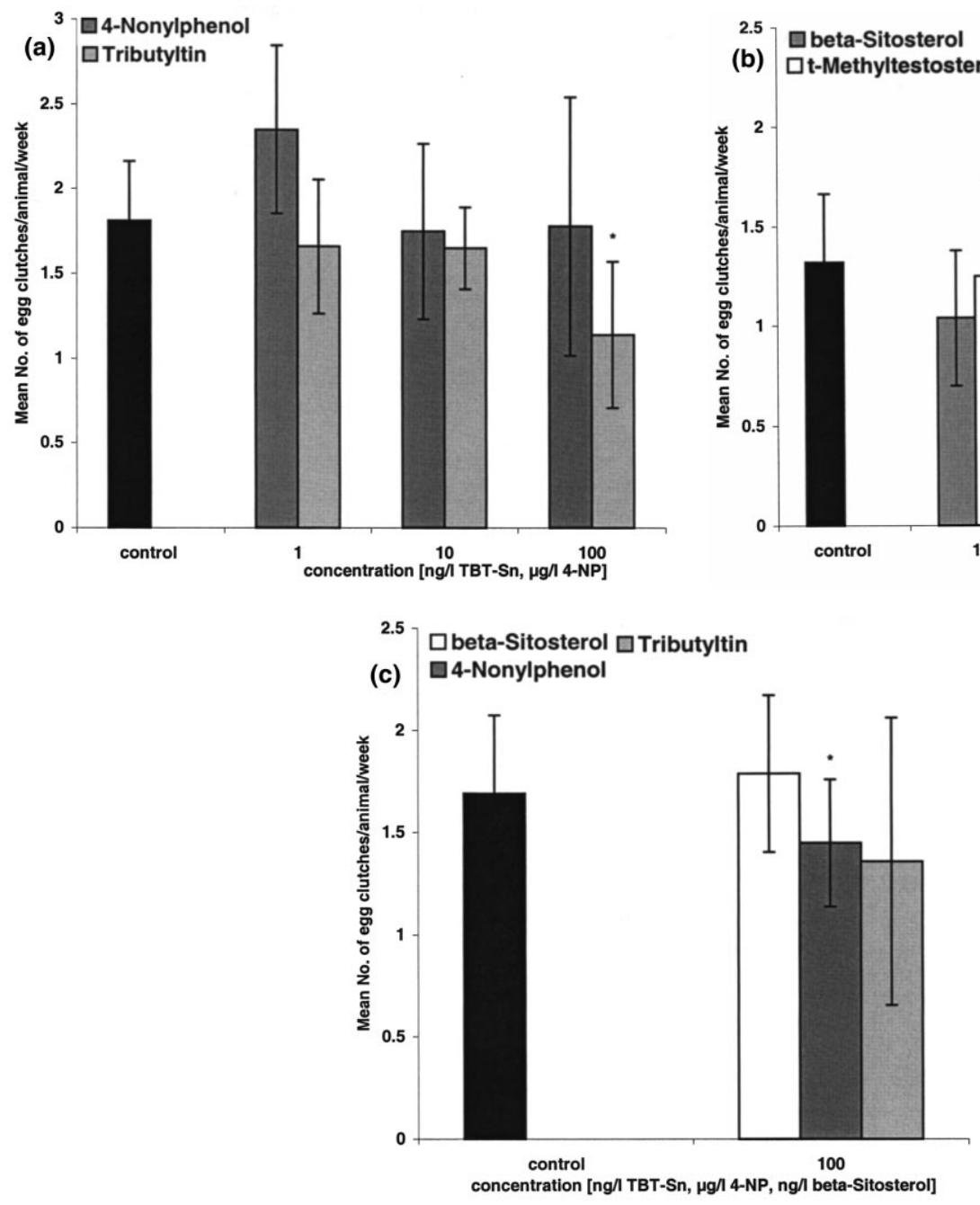

Fig. 3. (a) Fecundity after 7 weeks of exposure to 4-NP and Tributyltin. Presented are the mean values with standard deviations (S.D.) * Significant at $P \leq 0.05$ level according to Dunnett's multiple comparison test. (b) Fecundity after 8 weeks of exposure to $\beta$-sitosterol and $t$-methyltestosteron. Presented are the mean values with S.D. (c) Fecundity after 12 weeks of exposure to $\beta$-sitosterol, 4-NP and tributyltin. Presented are the mean values with S.D. * Significant at $P \leq 0.05$ level according to Student's $t$-test.

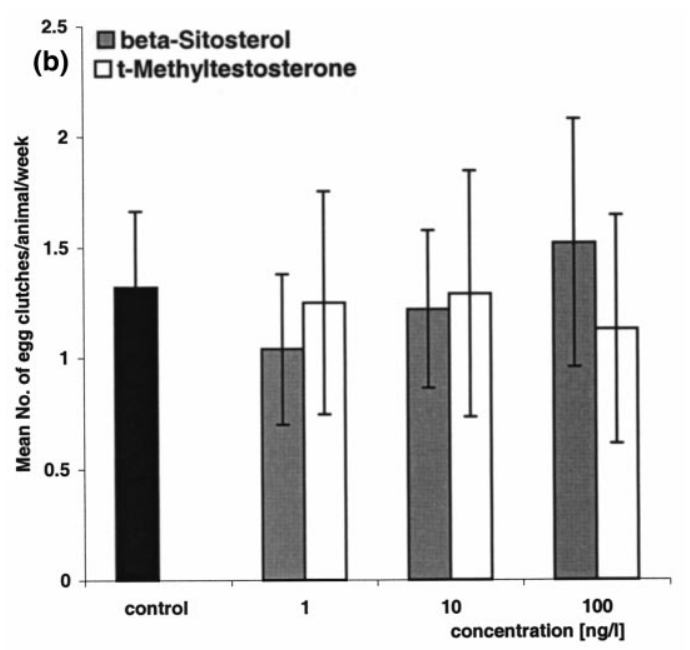

\section{Acknowledgements}

We would like to thank Dr U. Memmert for his interest and critical discussion and for giving the opportunity to carry out this study in the context of a Ph.D. thesis within the department of Ecotoxicology at RCC Ltd., Zelgliweg 1, CH-4452 Itingen. We would like to thank Beatrice Betschart and Cathrine Böglen for her expert technical assistance and the whole laboratory staff 

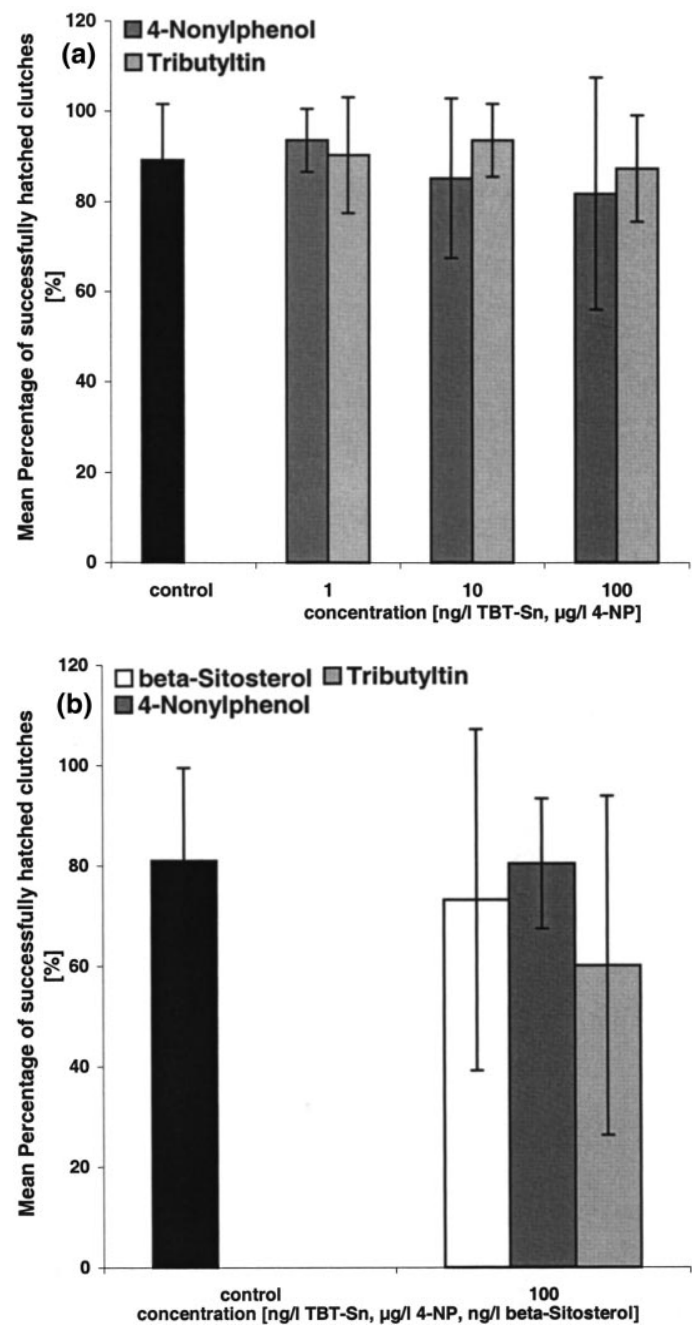

Fig. 4. (a) Fertility expressed as percentage of successfully hatched clutches after 7 weeks of exposure to 4-NP and tributyltin. Bars represent the mean values. (b) Fertility expressed as percentage of successfully hatched clutches after 12 weeks of exposure to $\beta$-sitosterol, 4-NP and tributyltin. Bars represent the mean values.

of the ecotoxicology for their helpful support. The company RCC Ltd. is gratefully acknowledged for providing the facilities and necessary equipment.

\section{References}

Arcand-Hoy, L.D., Benson, W.H., 1997. Fish reproduction: an ecological relevant indicator of endocrine disruption.
Env. Toxicol. Chem. 17, 49-57.

Bauer, B., Fioroni, P., Schulte-Oehlmann, U., Oehlmann, J., Kalbfus, W., 1997. The use of Littorina littorea for tributyltin (TBT) effect monitoring — results from the German TBT survey 1994/1995 and laboratory experiments. Environ. Pollut. 96 (3), 299-309.

Bettin, C., Oehlmann, J., Stroben, E., 1996. TBT induced imposex in marine neogastropods is mediated by an increasing androgen level. Helgoländer Meeresuntersuchungen 50 (3), 299-317.

Blackburn, M.A., Waldock, M.J., 1995. Concentrations of alkylphenols in rivers and estuaries in England and Wales. Water Res. 29 (7), 1623-1629.

Colborn, T., vom Saal, F.S., Soto, A.M., 1993. Developmental effects of endocrine-disrupting chemicals in wildlife and humans. Environ. Health Perspect. 101, 378-384.

Denton, T.E., Howell, W.M., 1989. Gonopodial morphogenesis in female mosquitofish, (Gambusia affinis) masculinised by exposure to degradation products from plant sterols. Environ. Biol. Fish 24 (1), 43-51.

Ellis, R., Stuthridge T., van den Heuvel, M.R., Dietrich, D.R., MacCarthy, L.H., Ling, N., Hogg, I.D., 1999. Potential for gonopodial morphogenesis, and behavioural abnormalities in mosquitofish (Gambusia affinis affinis) exposed to wastewater from a pulp and paper mill; comparison with the effects of stigmastanol. In: The 3rd Annual meeting of the Society of Environmental Toxicology and Chemistry, 25-29 May, 1999 Leipzig, Germany.

Fent, K., 1996. Ecotoxicology of organotin compounds. Crit. Rev. Toxicol. 26, 1-117.

Holm, L.W., 1945. Histological and functional studies on the genital tract of Lymnaea stagnalis appressa Say. Trans. Am. Microsc. Soc. 65, 45-68.

Jobling, S., Nolan, M., Tyler, C.R., Brighty, G., Sumpter, J.P., 1998. Widespread sexual disruption in wild fish. Environ. Sci. Technol. 32, 2498-2506.

Lech, J.J., Lewis, S.K., Ren, L., 1996. In vivo estrogenic activity of nonylphenol in rainbow trout. Fund Appl. Toxicol. 30 (2), 229-232.

Mac Latchy, D.L., Van der Kraak, G.J., 1995. The phytoestrogen $\beta$-sitosterol alters the reproductive endocrine status of the goldfish. Toxicol. Appl. Pharm. 134, 305-312.

Minchin, D., Bauer, B., Oehlmann, J., Schulte-Oehlmann, U., Duggan, C.B., 1997. Biological indicators used to map organotin contamination from a fishing port, Killybegs, Ireland. Mar. Pollut. Bull. 32, 188-195.

Oehlmann, J., Schulte-Oehlmann, U., Bauer, B., Markert, B., 1997. Einsatz TBT-induzierter Pathomorphosen bei Schnecken aus der Nord- und Ostsee zum biologischen Effektmonitoring. German J. Hydrogr. 7 (Suppl.), 77-98.

Oehlmann, J., Bauer, B., Minchin, D., Schulte-Oehlmann, U., Fioroni, P., Markert, B., 1998. Imposex in Nucella lapillus and intersex in Littorina littorea: interspecific comparison of two TBT-induces effects and their geographical uniformity. Hydrobiologia 378, 199-213.

Oehlmann, J., Fioroni, P., Stroben, E., Markert, B., 1996. Tributyltin (TBT) effects on Ocinebrina aciculata (Gastropoda: Muricidae): imposex development, sterilization, 
sex change and population decline. Sci. Total Environ. 188, 205-223.

Schulte-Oehlmann, U., Oehlmann, J., Fioroni, P., Bauer, B., 1997. Imposex and reproductive failure in Hydrobia ulvae (Gastropoda: Prosobranchia). Mar. Biol. 128, 257-266.

Schulte-Oehlmann, U., Bettin, C., Fioroni, P., Oehlmann, J.,
Stroben, E., 1995. Marisa cornuarietis (Gastropoda, Prosobranchia): a potential TBT bioindicator for freshwater environments. Ecotoxicology 4, 372-384.

Tate, T.M., Spurleck, J.O., Christian, F.A., 1997. Effects of glyphosate on the development of Pseusosuccinea columnella snails. Arch. Environ. Contam. Toxicol. 33, 286-289. 